\title{
Cowboys Stadium Mobility Assist Program: Accessible Routes and the Americans with Disabilities Act Accessibility Guidelines
}

\author{
MICHAEL MAHONEY
}

$\&$

JOHN MCMILLEN

California State University, Fresno

\section{INTRODUCTION}

Nearly one-third of American households have a member with at least one disability (The Leadership Conference on Civil and Human Rights, 2010). In 1990, the Americans with Disabilities Act (ADA) was enacted to ensure that people with disabilities have the same opportunities available to persons without disabilities (42 U.S.C. $\$ 12101$, et. seq., 2011). Referred to as the $20^{\text {th }}$ Century emancipation proclamation for people with disabilities (Harkin, 2008), the ADA mandates that public facilities must comply with strict building requirements to ensure that public services are accessible for people with disabilities.

Cowboys Stadium, the 2010 Sports Facility of the Year, is a $\$ 1.2$ billion public assembly facility which opened in 2009 (Arlington Insider, 2010). The stadium, designed to comply with the ADA, hosts a multitude of events, including religious ceremonies, business meetings, tradeshows, and sporting events. In March 2010, researchers conducted an on-site observation of Cowboys Stadium's first boxing match, an event which drew a crowd of 50,994 , the third largest attendance for an indoor fight in boxing history (Watkins, 2010). The purpose of the case study was to observe Cowboys Stadium's Mobility Assist (MA) program and the policies and procedures used to accommodate patrons with disabilities and determine whether the MA program complies with ADA guidelines for new stadiums. 
This research reviews the Americans with Disabilities Act Accessibility Guidelines (ADAAG) which require that at least one continuous, unobstructed route be provided to and from public facilities. The accessible route must comply with a multitude of ADAAG provisions, including Sections 207 Accessible Means of Egress; 502, Parking Spaces; and 503, Passenger Loading Zones, the foci of this study. Compliance with ADAAG is essential to providing a basic level of access for people with disabilities so they, their families, and friends can enjoy equal access to entertainment, recreation, and leisure.

\section{METHODOLOGY}

This research utilized a mixed-methods qualitative case study and legal research analysis to determine ADA compliance. The data for this study were collected from January through October 2010 , by direct observation, face-toface interviews, email correspondence, telephone calls, review of supplemental stadia documents and ADA legal requirements. Prior to the onsite evaluation, researchers developed a legal audit checklist based on the provisions of Chapter Four, Accessible Routes, and Chapter Eight, Wheelchair Spaces, of the ADAAG. Researchers utilized this checklist during the nonevent day tour of the venue and during participant interviews.

In February, researchers conducted a three-day on-site evaluation. During the first day, researchers observed the MA program at a live event. Researchers observed three phases of the MA program: drop-off and loading points, access routes, and wheelchair seating assignments. Researchers recorded field notes, took photographs, and interviewed randomly selected MA staff. On the second and third days, researchers interviewed stadium personnel and took measurements of ten randomly selected disabled seating locations and pathways and compared these measurements to current legal compliance mandates required by ADAAG. Measurements were taken of wheelchair stadium seating spaces, companion seats, and designated aisle seats by width, depth, and approach.

Four venue and event personnel were interviewed face-to-face. The interview pool consisted of venue and event management administrators with substantial experience as senior level stadium management, guest services management, logistical operations, and contracted vendor administration, since these areas are essential to administering and operating MA programs. Participants were purposefully selected based on their firsthand knowledge of venue and event management and their job responsibilities related to the MA 
program. Based on these criteria, two participants in venue management and two contracted vendors were selected and interviewed. Venue management participants worked in senior administrative positions and were responsible for all aspects of the MA program. The contracted vendors worked closely with guest services management and logistical operations and were responsible for implementing the transportation aspects of the MA plan.

Interviews followed a semistructured interview guide and were developed in three areas based on the provisions of Chapter Four, Accessible Routes, and Chapter Eight, Wheelchair Spaces, of the ADAAG. The first area concentrated on wheelchair and seating accessibility. The second area involved accessible routes to and from leisure events. The third area investigated wheelchair spaces and the needs of elderly guests with disabilities. Researchers probed participant responses to pursue in-depth information concerning these three areas.

\section{Data Analysis}

Notes were independently recorded during all interviews and responses were recorded on the legal audit checklist within the three focus areas. Researchers worked inductively and iteratively to give meaning and structure to data. Researchers independently read through the interview notes, legal audit checklist, field notes, supplemental data, and observations separately. Researchers then collaborated and compared and contrasted individual records for consistency, meaning, and interpretation. Full agreement was reached in all cases. Data were coded and categorized within the ADA and ADAAG three focus areas (wheelchair and seating accessibility, accessible routes, and wheelchair spaces). Data analysis involved three strategies: direct interpretation of the individual instance, categorical aggregation of multiple instances, and a legal analysis. Categorical aggregation allowed the emergence of meaning from the repetition of themes. Direct interpretation allowed the emergence of meaning from a single instance of data, such as a participant's specific comment regarding the ADA.

The ADA requires new stadiums to be accessible to people with disabilities. To determine accessibility, researchers conducted a legal analysis of the Cowboys Stadium's MA program to investigate whether it accommodates wheelchair and seating accessibility of elderly and disabled guests according to Chapter Four, Accessible Routes, and Chapter Eight, Wheelchair Spaces of the ADAAG. 


\section{OVERVIEW OF THE ADA AND ADAAG}

In 2010, the Americans with Disabilities Act celebrated its 20th anniversary as a public law designed to eliminate barriers for people with disabilities. Prior to the landmark legislation, people with disabilities faced numerous challenges outside of their disability. Bumpy walking trails, stairs, parking stalls, and concrete curbs were just a few of the significant obstacles that limited access to and from public venues. In order to remove these barriers, the ADA requires elevators, ramps, curb cuts, and other route specific guidelines for newly constructed and altered public accommodations (42 U.S.C. $§ 12101$, et. seq., 2011).

Title II and Title III of the ADA are most applicable to sport properties (Grady \& Ohlin, 2004). Title II mandates that public entities, such as sport and entertainment venues, give people with disabilities an equal opportunity to benefit from all of their programs, services, and activities (42 U.S.C. $\S 12132$, 2011). Title III requires that "places of public accommodation" be designed, constructed, or altered to be accessible (Chapman v. Pier 1 Imports., 2009). A place of public accommodation is a facility operated by a private entity whose operations affect commerce and fall within at least one of twelve categories including stadiums, such as Cowboys Stadium (42 U.S.C. $\$ 12186(b)(5)$, 2011).

Under Title III, the degree of accessibility to a facility depends on the date of the design and construction of the facility. For example, places of public accommodations built before January 26, 1993, are required only to remove architectural barriers where such removal is "readily achievable" (Hazard, 2005). For places of public accommodation built after January 26, 1993, facilities must be "readily accessible," except where the requirements are structurally impractical to meet (Hazard). However, new buildings must comply with strict accessibility standards (28 C.F.R. Part 36, Subpart D, 2011) as well as comply with the Americans with Disabilities Accessibility Guidelines (ADAAG) (28 C.F.R. 36.406, 2011). Failure to abide by the ADAAG in new construction is evidence of intentional discrimination against people with disabilities (Access Now et al. v. S. Florida Stadium Corp. et al., 2001).

To ensure compliance with the ADA, Congress charged the U.S. Access Board (Board) with establishing guidelines for accessible design and construction. Subsequent to publishing the first ADAAG in 1991 the Board determined that its guidelines would be more effective if they reflected the current requirements of the model building codes and standards (Access 
Board, n.d.). Therefore, the Board appointed a federal advisory committee to draft a new ADAAG patterned after the model building codes of the Building Officials and Code Administrators, International Council of Building Officials, and Southern Building Code Congress International, the "legacy" code organizations that later combined to become the International Code Council (ICC) (Black, 2006).

Like most federal regulations, ADAAG were developed under a rulemaking process that invites public comment through publication in the Federal Register (Access Board, n.d.). Changes and additions to ADAAG are also published through the same rulemaking process that provides public notice and the chance to comment (Access Board). In 1991, the Board called on the U.S. Department of Justice (DOJ) to establish construction regulations that apply to commercial construction, public accommodations, and state and local governments (Black, 2006). Any future changes the Board makes to the ADAAG do not become enforceable until they are adopted into the standards maintained by DOJ (Access Board).

Because the ADA is a civil rights law, enforcement of its design requirements are not overseen by a local building code official (Access Board, n.d.). Instead, when discrimination is alleged ADAAG requirements and other provisions of the law are enforced through private suit or by certain federal agencies (Access Board, n.d.). To prevail in a Title III lawsuit, the plaintiff must prove: (1) s/he has a disability, (2) the defendant's facility is a place of public accommodation, (3) and the plaintiff was denied full and equal treatment because of his disability (Pascuiti v. New York Yankees, 1999).

Some states have adopted ADAAG as their accessibility code and implement its provisions through state and local building code officials in the same way as other applicable building regulations are applied, reviewed, and enforced (Access Board, n.d.). The Department of Justice may file lawsuits in federal court to enforce the ADA, and courts may order compensatory damages and back pay to remedy discrimination if the Department prevails (Department of Justice, n.d.). Under Title III, the Department of Justice may also obtain civil penalties of up to $\$ 55,000$ for the first violation and $\$ 110,000$ for any subsequent violation (Department of Justice). In addition, private individuals may bring lawsuits or file a complaint with the Attorney General who is authorized to bring lawsuits in cases of general public importance or where a pattern of discrimination is alleged (Id.).

Since the publication of the ADAAG in 1996, the U.S. Access Board and model code community have sought to harmonize the differences between their respective accessibility requirements, with the latter having the stated 
goal of meeting or exceeding the federal ADA and Fair Housing requirements wherever possible (Black, 2006). This has been an ongoing process, with what is now the ICC making amendments to the International Building Code (IBC) based on interim drafts of the new ADAAG, and the Access Board modifying its provisions in light of new developments in the IBC and the ICC standards (Black). In 2010, the Board published its most recent ADAAG (Id.). These standards were adopted by the Department of Justice and went into effect March of 2011 with compliance required in March of 2012 (Access Board, 2010).

The ADAAG includes separate scoping sections for facilities covered under the ADA, but references a single set of simplified technical requirements. Scoping provisions spell out the spaces and elements that must meet the technical criteria of the ADAAG (Access Board, 2010). For example, the new ADAAG establishes one set of accessible reach ranges and maneuvering clearances to which all other sections refer.

Scoping provisions for privately owned facilities that are open to the public are different from those owned by federal, state, or local governments, but technical requirements for accessible elements are the same. For example, privately owned facilities that are less than three stories, or less than 3,000 square feet per floor, do not require an elevator (Access Board, 2010).

In sum, the updated ADAAG contains the scoping and technical requirements for accessibility to buildings and facilities by individuals with disabilities under the ADA (Access Board, 2010). These ADAAG must be applied during the design, construction, and alteration of buildings and facilities covered by Titles II and III of the ADA to the extent required by regulations issued by federal agencies, including the DOJ and the Department of Transportation (Access Board).

\section{ADAAG and Stadium Access Routes}

While the ADA and ADAAG mandate strict design procedures for new or altered stadia, they also require sport and entertainment venues to provide an accessible route to and from the event. According to Chapter 4, Accessible Routes, the ADAAG require that:

Accessible routes shall consist of one or more of the following components: walking surfaces with a running slope not steeper than 1:20, doorways, ramps, curb ramps excluding the flared sides, elevators, and platform lifts. All components of an accessible route 
shall comply with the applicable requirements of Chapter 4 (Access Board, 2010, 402.2)

In other words, ADAAG requires accessible routes to and from a public sport and entertainment venue to comply with standards based on the location, width, passing space, head room, surface, slope, changes in level, doors, egress, and areas of rescue assistance, unless otherwise modified by specific provisions outlined ADAAG (Access Board, n.d.). Specifically, according to section 502, if parking spaces are provided, accessible spaces for cars and vans also must be provided. Restrictions apply as to the number of spaces, width of parking stalls, access, and passenger loading zones (Access Board, 2010). Furthermore, accessible parking spaces must be the closest parking spaces to the accessible entrances and must be on an accessible route to the entrances (Access Board).

Under the advisory provision, 502.3, accessible routes must connect parking spaces to accessible entrances. In parking facilities where the accessible route must cross vehicular traffic lanes, marked crossings are designed to enhance pedestrian safety, particularly for people using wheelchairs and other mobility aids. Where possible, it is preferable that the accessible route not pass behind parked vehicles.

Under the ADAAG scoping guidelines, 206.2.1, Site Arrival Points, at least one accessible route must be provided to the site from accessible parking spaces and passenger loading zones; public streets and sidewalks; and public transportation stops to the building or facility entrance they serve (Access Board, 2010). In addition, the accessible routes must serve all of the accessible entrances on the site. Similarly, under section 503, Passenger Loading Zones, if passenger drop-off areas are provided, they must be accessible and an accessible route must connect each accessible drop-off area with the accessible entrance(s). Where load and unload areas have more than one loading or unloading position, at least one loading and unloading position must be on an accessible route. Ramps must be provided if the drop-off area is next to a curb (Access Board, 2010).

Providing an access route to a sport and entertainment venue is only part of a sport organization's legal obligations under the ADA. ADAAG also include specifications for "accessible means of egress," emergency alarms, and signage (Savage v. City Place Limited Partnership, 2004). An accessible means of egress is a continuous and unobstructed way of egress travel from any point in a building or facility that provides an accessible route to an area of refuge, a horizontal exit, or a public way (Access Board, 2010). Most of the criteria for accessible routes, such as width and the treatment of elevation 
changes, are also applied to accessible means of egress to ensure access for persons with disabilities, including those with mobility impairments (Access Board). Multi-story buildings, such as Cowboys Stadium, can pose a particular challenge to accessible means of egress because the standard means of access between floors are typically taken out of service in emergencies for safety reasons (Grady \& Andrew, 2007).

\section{COWBOYS STADIUM AND ADA ACCESS ROUTE COMPLIANCE}

Cowboys Stadium is a $\$ 1.2$ billion structure and encompasses 73 acres with an overall footprint of 140 acres (Wood, 2009). Architects and engineers designed, and construction personnel built the multi-use facility utilizing over 26,000 tons of steel and 19 million pounds of truss work. The venue has over 1,600 toilets, 22 escalators, 18 elevators and 10 major stairways, 10 bars or clubs, 15,000 club seats and 300 luxury suites, and a 70 foot by 160 foot center-hung video board (Cowboys Stadium, 2010).

To accommodate guests, Cowboys stadium has approximately 12,000 onsite parking spaces. Thirteen of the 15 numbered parking lots are paved and two lots are grass parking. Stadium seating is configured with 1,201 wheelchair platform seats or limited mobility seats for a traditional Cowboys' football game. As of March 2011, the largest single-event attendance recorded for the stadium was 108,713 for the 2010 NBA All-Star Game - the largest attendance ever for a basketball game. The occupancy certificate issued by the city of Arlington, Texas lists the maximum capacity for the venue at 111,947 (Mosier, 2010).

In order to achieve ADA and ADAAG compliance, Cowboys Stadium has instituted a MA program. The safe and timely transport of guests with disabilities and mobility limitations from 11 "official" event parking lots to the venue (inbound) and post-event reversal (outbound) is the primary charge of the MA plan. The MA is comprised of three distinct entities: senior level stadium management; logistical operations and administration by Central Parking System (CPS); and contracted transport coordination services (CPS, 2010). According to the MA plan, transportation is provided for any constituent group needing assistance, including but not limited to, VIP's, media, staff, volunteers, teams, team families, sponsors, general spectators, and those who have special needs as determined by the patron. Patrons with special needs, or mobility limitations, ranged from elderly and pregnant guests, to other temporary or permanent physical limitations. 
Under ADAAG scoping standards, 208.3.1 General, parking spaces complying with 502 that serve a particular building or facility must be located on the shortest accessible route from parking to an entrance and comply with 206.4 (Access Board, 2010). Where parking serves more than one accessible entrance, parking spaces complying with 502 shall be dispersed and located on the shortest accessible route to the accessible entrances. However, parking spaces are permitted to be located in different parking facilities if substantially equivalent or greater accessibility is provided in terms of distance from an accessible entrance or entrances, parking fee, and user convenience (Access Board).

Cowboys Stadium's current parking guidelines meet or exceed ADAAG sections 502 and 503 parking and passenger loading zone requirements. For events held at Cowboys Stadium, 225 accessible parking spaces are designated as reserved, i.e., striped, painted, and marked with required ADA signage. On event-day, researchers noted 20 additional parking spaces reserved in each of the 11 paved and striped lots with movable cones, thereby increasing accessible parking to 445 , which meets ADAAG 502-503 standards. The procedure of pre-assigning 20 additional parking spaces for each of the paved official stadium lots is standard for all events at the venue and exceeds ADAAG parking standards.

Accessible parking spaces are available in 11 of the official paved parking lots and are issued on a first-come, first-serve basis and therefore meet ADAAG section 502 (Access Board, 2010). Cash and permit parking are enforced as guests are required to have a parking pass for designated lots to park in an accessible parking space (Cowboys Stadium Parking, 2010). Cowboys Stadium's transportation and parking plan also honors guests with Disabled Veterans \& Purple Heart placards to park for no charge in two lots (CPS Event Sheet, 2010).

Any vehicle arriving at one of the lots with the proper state-issued disability plate or placard is directed by parking lot staff to an accessible parking space. Once parked, the guests with disabilities or mobility limitations are directed to the MA shuttle load zone provided in the respective parking lots. These designated areas are appointed with blue flags and MA signage. Upon arrival of the MA shuttle, patrons are transported from the parking lot to the assigned entry gate following a dedicated path of travel per ADAAG advisory provision 402 .

According to ADAAG scoping standards, 213 Toilet Facilities and Bathing Facilities, where toilet facilities are provided, they must comply with section 213 (Access Board, 2010). Portable toilet units must be identified by 
the International Symbol of Accessibility complying with 703.7.2.1 (Access Board). Cowboys Stadium parking lots are compliant with section 213 and portable toilet units are provided in the respective lots according to 703.7.2.1.

Dependent upon guests needs, upon arrival at entries A, D, J, or G of Cowboys Stadium, events services staff escort guests who request assistance to their respective seats via wheelchair assistance (Cowboys Stadium Guest with Disabilities, 2010). Within the venue, two accessibility teams of 12 members each are responsible for accommodating guests with disabilities or mobility limitations. Services provided include, but are not limited to, documentation of requested services by specific guests, processing a reservation, and coordinating logistics for post-event transports from the guest seating area to one of the four exterior designated outbound ADA tents located near exits $\mathrm{A}, \mathrm{D}, \mathrm{J}$, and $\mathrm{G}$.

The MA program also incorporates radio communication between shuttle drivers, parking lot attendants, and has an ADA coordinator and stadium control room in order for guests with disabilities to be served in an efficient manner. The ADA coordinator is responsible for on-site monitoring of MA requests and timely deployment of shuttles to areas requiring assistance. Guests with disabilities or mobility limitations who utilize the MA shuttle are provided with a locator card by the shuttle driver indicating the location to return after the event for MA shuttle pick-up (CPS, 2010).

The MA shuttle is available on event days from each of the 11 designated venue parking lots to the facility. Shuttles are staffed and operational upon the opening of all Cowboys Stadium parking lots, running continuously up to an hour and a half after the event (CPS, 2010). The MA service is limited to those guests needing the service and one companion. Post-event (outbound) MA shuttles are staged at stadium exits A, D, J, and G. Guests with disabilities or mobility limitations are shuttled from these four designated pick-up zones located outside of the stadium, following a "dedicated path of travel" back to the respective lot where their vehicle is parked.

According to MA program documents, up to $15 \mathrm{MA}$ carts are assigned to each event at Cowboys Stadium, including wheelchair accessible transport for those patrons who park remotely (CPS, 2010). Event day requirements of MA transportation staff include: reporting to the ADA coordinator of guest needs; checking-out required equipment (e.g., radio, blue flags, shuttle cart, and key); attending event briefing; collecting event and log sheets; deploying to assigned lots; and reversing the process at completion of shift or event. The ADA coordinator is responsible for collecting shuttle $\log$ sheets and providing 
copies to management of stadium operations and coordinates all logistics and parking for guests with disabilities.

In accordance with the Cowboys Stadium Game Day Staff Handbook (2010) all staff members of subcontractors and vendors are required to follow Game Day Staff policies when assigned to Cowboys Stadium. As such, gratuities or tips may never be solicited or accepted under any circumstances.

Risk management and transportation requirements of the MA service include: trained personnel; maintained equipment and shuttles; utilization of safe travel routes separating MA shuttles from the majority of pedestrians; sector patterned travel via placement of safety cones; aerial surveillance from stadium control room; efficient radio communication; and documentation of MA transport log and requests (P. Turner, personal communication, March 14, 2010). Outbound traffic flow, both vehicular and pedestrian, proved to be logistical challenges to the MA service as shuttles transited back-and-forth from the stadium to the parking lots took longer than anticipated and some guests became restless awaiting the next shuttle. This potentially could be problematic for those passengers with special needs. For example, delayed transport could impact a diabetic who needs immediate medication if it is stored in their remotely-parked vehicle.

\section{DISCUSSION AND CONCLUSION}

Cowboys Stadium meets or exceeds ADAAG Sections 207 Accessible Means of Egress; 502, Parking Spaces; and 503 Passenger Loading Zones. While Cowboys Stadium's MA program incorporates many commendable features, accessibility improvements still can be made. For example, not all guests can afford to pay the Cowboys Stadium parking fee ( $\$ 50$ for the case study event) and park in one of the 11 dedicated lots, thereby forcing some guests to find alternative parking which may not provide an accessible path to the stadium. In addition, while there is abundant parking spaces at Cowboys Stadium, public transit may not be fully meeting the needs of older adults and people with physical impairments who park outside of the stadium footprint. Researchers also queried whether patrons with special needs were able to withstand a prolonged wait period in the queuing zone for outbound taxis since some guests waited over one hour.

In addition, the four accessibility shuttle tents located near entries A, D, J, and G, while compliant with ADA standards, should incorporate differentiation of symbols or colors to expedite awareness of the MA program. It is also recommended that all tents or similar structures be located on a flat, 
stable, firm, and slip resistant surface as compared to the observed grass/terrain locations.

The ADA shuttle log used to document MA arrivals includes the following helpful categories: driver, assignment, date, lot, patron need, number of people, and comments section (ADA Shuttle Log, 2010). However, researchers recommend adding a time indicator and data entry system to store all information to better plan for future events. Additional enhancements could also include GPS tracking to monitor the inbound and outbound MA program carts. This would improve efficiency of the MA program to better meet the needs of waiting patrons.

Based on this research, five core principles are recommended for adoption by similar sport and entertainment venues: (1) a dedicated and trained mobility assist staff, such as a wheelchair escort team, should be utilized at every event, (2) mobility assistance should be provided upon the guest's request, not venue or staff determination, (3) all mobility transports must have an accessible inbound and outbound dedicated path of travel, (4) an ADA shuttle log should be used to monitor guest requests and needs, and (5) a mobility assist program coordinator to oversee the mobility assist program (McMillen \& Mahoney, 2011).

In order to comply with the ADAAG, sport organizations are advised to review their current access routes and determine whether they meet ADAAG and implement staff training to ensure compliance. Regardless of planning and overall design of any mobility assist program, training remains critical to its success (Skulski, Bloomer \& Chait, 2002). From the front-line parking attendant and auditor, to the mobility assist driver and wheelchair services event staff, all the way to the facility director and transportation services contractor, training is an essential component in order to effectively serve patrons with disabilities (LaMaster, Gall, Kinchin, \& Siedentop, 1998). At a minimum, general training, such as new-hire and yearly refresher courses on disability awareness and appropriate terminology, should be conducted at all levels. Training should be tailored to job responsibilities (Huston-Wilson, Dunn, van der Mars, \& McCubbin, 1997). For example, mobility assist programs should be detailed with specific procedures, such as taking requests for accommodations at the guest services center, greeting patrons with disabilities when entering a passenger drop-off zone at the stadium, accessibility shuttle tent, or the stadium parking lot (McMillen \& Mahoney, 2011).

In order to differentiate mobility assist transports from other venue and event day carts, all mobility assist carts used at a sport or entertainment venue 
should be outfitted with a visual cue, such as a flashing light and drivers should wear coordinating apparel to improve visibility of the program. Venues should also monitor queuing zones to minimize wait times and provide sheltered areas and accessible benches for guests with special needs.

By implementing the five core principles and other recommendations, not only will sport organizations and venue and parking operators comply with the ADAAG, but more importantly provide patrons an equitable experience at sport and entertainment venues. Furthermore, additional research is needed in the area of mobility assist programs in order to advance the sport and recreation industry's understanding of the ambulatory needs of all guests.

\section{ABOUT THE AUTHORS}

DR. Michael Mahoney is an Assistant Professor at California State University, Fresno where he coordinates the Sports and Entertainment Facility Management (SEFM) emphasis, and certificate option. Dr. Mahoney is an Editorial Review Board Member for the Journal of Venue and Event Management (JVEM), and serves on both the College/University Sports Program, and Scholarship committees for the Stadium Managers Association (SMA).

DR. JOHN MCMILLEN is an Associate Professor at California State University, Fresno where he coordinates the Sport Administration undergraduate and graduate programs. Dr. McMillen received his law degree from Drake University and his PhD from the University of Nebraska-Lincoln

\section{REFERENCES}

Access Board (2010). Department of Justice's ADA Standards for Accessible Design. Retrieved March 30, 2011, from http://www.access-board.gov/adaaba/ada-standards-doj.cfm

Access Board (n.d.). Using ADAAG. Retrieved March 30, 2011, from http://www.access-board.gov/adaag/about/using\%20adaag.htm

Access Now, Inc. v. South Florida Stadium Corp., 161 F. Supp. 2d 1357 (S.D. Fla. 2001).

ADA Shuttle Log (2010). Cowboys Stadium document. Arlington, TX.

Americans with Disabilities Act, 42 U.S.C. §12101, et. seq., 2011. 
Arlington Insider. (2010). Cowboys Stadium wins "Sports Facility of the Year." Retrieved March 30, 2011, from http://insider.arlington.org/2010/05/21/ cowboys-stadium-wins- $\% \mathrm{E} 2 \% 80 \% 9 \mathrm{C} 2010$-sports-facility-of-the-year $\% \mathrm{E} 2 \%$ $80 \% 9 \mathrm{D} /$

Black, B. (2006). Commentary on and analysis of the 2004 Americans with Disabilities Act Accessibility Guidelines. BDBlack Codes, Inc.: Perry, New York.

Chapman v. Pier 1 Imports Inc., 631 F.3d 939 (9th Cir. 2009).

Central Parking System. (2010). ADA Transportation Plan. Cowboys Stadium document. Arlington, TX.

Central Parking System. (2010). Event Briefing Sheet. Cowboys Stadium document. Arlington, TX.

Cowboys Stadium (2010). Cowboys Stadium facts. Cowboys Stadium document. Arlington, TX.

Cowboys Stadium game day staff handbook (2010). Cowboys Stadium document. Arlington, TX.

Department of Justice (n.d.). ADA enforcement. Retrieved from March 31, 2011, http://www.ada.gov/enforce.htm

Grady, J., \& Andrew, D.P.S. (2007). Equality of access to emergency services for people with disabilities under the Americans with Disabilities Act. Journal of Legal Aspects of Sport, 17(1), 1-25.

Grady, J. \& Ohlin, J. (2004). The application of Title III of the ADA to sport websites. Journal of Legal Aspects of Sport, 14(2), 145-161.

Harkin, T. (2008). In Iowa's interest: Protecting the rights of Iowan's with disabilities. Retrieved March 31, 2011, from http:/harkin.senate.gov/ press/column.cfm?i $=295129$

Hazard, T. (2005). On the drawing board: New ADA access rules. Law Trends \& News. Retrieved March 31, 2011, from http:/www.abanet.org/genpractice/ newsletter/lawtrends/0506/realestate/adaaccessrules.html

Huston-Wilson, C., Dunn, J.M., van der Mars, H., \& McCubbin, J. (1997). The effect of peer tutors on motor performance in integrated physical education classes. Adapted Physical Activity Quarterly, 14, 298-313.

LaMaster, K., Gall, K., Kinchin, G., \& Siedentop, D. (1998). Inclusion practices of effective elementary specialists. Adapted Physical Activity Quarterly, 15, 64-81. 
McMillen, J. \& Mahoney, M.P. (in press). Leisure and Disability: Mobility assist program for aging and older adults. International Journal on Disability and Human Development.

Mosier, J. (2010). Cowboys Stadium's star has risen in year since its Arlington debut. Dallas News.com. Retrieved March 31, 2011, from http://www.dallasnews.com/sharedcontent/dws/dn/latestnews/stories/060610 dnmstadiumanniversary. $19 \mathrm{c} 5 \mathrm{~b} 66 . \mathrm{html}$

Pascuiti v. New York Yankees, 108 F. Supp. 2 d 258 (S.D.N.Y., 1999).

Savage v. City Place Limited Partnership, 2004 WL 3045404 (Md. Cir. Ct. 2004).

Skulski, J.K., Bloomer, R., \& Chait, J. (2002, August). Accommodating patrons with disabilities: $A$ survey of ticket and accommodation policies for performance venues, theaters and sports arenas. National Center on Accessibility: Bloomington, IN.

The Leadership Conference on Civil and Human Rights (2010). The 2010 census and people with disabilities: High stakes and major opportunities. Retrieved March 31, 2011, from http://www.civilrights.org/census/censusresources/ census-and-people-with-disabilities.pdf

Watkins, C. (2010). Crowd is one of largest for fight. ESPN.com. Retrieved March 31, 2011 from http://sports.espn.go.com/dallas/news/ story?id $=4993511$

Wood, S. (2009). NFL heightens look into Cowboys Stadium video screen. Retrieved March 31, 2011 from http://www.usatoday.com/sports/ football/nfl/cowboys/2009-08-24-cowboys-stadium-video_N.htm 